\title{
Akutt respirasjonssvikt ved alvorlig sykdom og skade
}

\begin{abstract}
Sammendrag
Bakgrunn. Akutt respirasjonssvikt er den vanligste årsaken til intensivmedisinsk behandling. Det oppstår hos $20-75 / 100$ 000/år og skyldes som oftest akutte betennelsesforandringer i lungevevet. I denne artikkelen gis en oversikt over kliniske forhold, etiologi, patofysiologi og behandling ved akutt alvorlig respirasjonssvikt, med hovedvekt på svikt fremkalt av sekundære betennelsesforandringer
\end{abstract}

\section{Materiale og metode. Oversikten representerer ikke noen systematisk litteraturgjennomgang - den bygger på forfatterens kliniske intensivmedi- sinske erfaring og lungesviktrelaterte forskningsarbeid samt hans private arkiv og et avgrenset litteratursøk i Medline.}

Resultater. Akutt respirasjonssvikt kan skyldes sykdom eller skade som påvirker lungene direkte. Alvorlige infeksjoner eller vevsskade andre steder i kroppen kan også forårsake slik svikt - ved at aktiverte blodceller og proinflammatoriske stoffer følger blodstrømmen til lungene, der de utløser en sekundær betennelsesreaksjon. Den sistnevnte type respirasjonssvikt er mest alvorlig, og har en dødelighet i sykehus i området 30-50\%.

Fortolkning. Det finnes ingen spesifikk behandling av den sekundære betennelsesreaksjonen, den er som oftest reversibel når de utløsende skadeeller sykdomsprosesser går tilbake. Respiratorbehandling kan hindre at alvorlig hypoksemi gir tilleggsskader av både primært og sekundært affisert vev. Med moderne intensivbehandling skyldes bare $10-15 \%$ av dødsfallene ved akutt respirasjonssvikt selve lungesvikten. De fleste dør fordi de i tillegg utvikler svikt av andre organer (multiorgansvikt).

\section{Helge Opdahl}

helge.opdahl@ulleval.no

Nasjonalt kompetansesenter for NBC-medisin Oslo universitetssykehus, Ullevål 0407 Oslo

Alvorlig respirasjonssvikt hos tidligere lungefriske skyldes som oftest en utbredt betennelsesprosess i lungevevet. Hvis årsaken er infeksiøs (f.eks. bakteriell pneumoni), går prosessen som regel tilbake ved effektiv behandling av det utløsende agens. Ved ikkeinfeksiøse årsaker, som mekanisk skade av lungevevet, aspirasjon av mageinnhold til luftveiene eller inhalasjon av skadelige gasser, finnes det ingen spesifikk behandling.

En betennelsesprosess kan også oppstå sekundært til brudd- eller vevsskader andre steder i kroppen eller til infeksjoner hvor fokus er lokalisert fjernt fra lungene. Slike prosesser er en vanlig årsak til at pasienter trenger respiratorbehandling. Tilbakegang av svikten er betinget av hvorvidt den utløsende årsak er reversibel. I denne artikkelen er det først og fremst respirasjonssvikt som oppstår sekundært til sykdomsprosesser utenfor thorax som omtales.

\section{Materiale og metode}

Grunnlaget for artikkelen er et ikke-systematisk litteratursøk i Medline, der det er gjort et skjønnsmessig utvalg av artikler basert på forfatterens erfaring innen feltet. I tillegg er det brukt artikler hentet fra forfatterens eget litteraturarkiv. Forfatteren har over 20 års erfaring fra kirurgiske intensivavdelinger ved Oslo universitetssykehus, Ullevål, og har doktorgrad fra Universitetet i Oslo i 1993 med vekt på nøytrofile granulocytters betydning for utvikling av akutt lungesviktsyndrom.

\section{Lungeshunt og oksygenering av arterieblod}

Lungeshunt oppstår når deler av blodet som strømmer gjennom lungene passerer lungevev hvor oksygenopptaket fra alveolene er redusert eller opphørt. Dette fører til at arterieblodets oksygentrykk $\left(p_{\mathrm{a}} \mathrm{O}_{2}\right)$ blir lavere enn det som forventes ut fra oksygentrykket $\mathrm{i}$ inspirasjonsluften. Forskjellen mellom aktuell og forventet $p_{\mathrm{a}} \mathrm{O}_{2}$ avhenger av forholdet mellom de fraksjoner av blodet som passerer alveolområder med henholdsvis normal, nedsatt eller ingen ventilasjon (fig 1). Vanlige årsaker til nedsatt ventila- sjon er økt luftveismotstand eller at lungevevets elastisitet er redusert. Opphørt ventilasjon ses først og fremst i områder hvor alveolene er fylt av ødemvæske eller puss eller har falt sammen (atelektaser).

I klinisk sammenheng angis shunten ofte som forholdet mellom oksygentrykket i arterieblodet og fraksjonen av $\mathrm{O}_{2} \mathrm{i}$ inspirasjonsluften, $p_{\mathrm{a}} \mathrm{O}_{2} / \mathrm{F}_{\mathrm{i}} \mathrm{O}_{2}$, eller som differansen mellom beregnet oksygentrykk $\mathrm{i}$ alveolene $\left(p_{\mathrm{A}} \mathrm{O}_{2}\right)$ og det som måles $\mathrm{i}$ arterielt blod: $p_{\mathrm{A}} \mathrm{O}_{2}-p_{\mathrm{a}} \mathrm{O}_{2}$.

\section{Akutt lungesviktsyndrom}

Akutt respirasjonssvikt etter store skader og sjokktilstander, uavhengig av om skaden innbefattet lungene, har lenge vært kjent blant militærleger og skadekirurger. Tilstanden ble ofte kalt «sjokklunge». Den ble erkjent som et eget sykdomsbilde først etter at Asbaugh og medarbeidere beskrev den som et syndrom i 1967 (1) og kalte det «acute respiratory distress syndome» (ARDS). På norsk er betegnelsen «akutt lungesviktsyndrom». Betegnelsen økte forståelsen for at slik respirasjonssvikt ikke var en hyperakutt pneumoni, men at svikten kunne oppstå sekundært til en rekke andre sykdommer og skader.

\section{Symptomer og diagnose}

Lungenes elastisitet er redusert, og nedsatt oksygeninnhold i blodet gir økt trettbarhet i respirasjonsmuskulaturen. Symptombildet likner pneumoni, med anstrengt ventilasjon, takypné, takykardi og cyanose. Funnene ved auskultasjon er ofte uspesifikke. Ved en internasjonal konsensuskonferanse i 1990årene (2) vedtok man følgende definisjon av akutt lungesviktsyndrom:

\section{Hovedbudskap}

- Akutt respirasjonssvikt er den vanligste årsaken til intensivbehandling

- Svikten skyldes akutte betennelsesprosesser i lungevevet. Betennelsesprosessene kan skyldes forhold både i og utenfor lungene

- Det finnes ingen spesifikk behandling av ikke-infeksiøs akutt respirasjonssvikt

- Vellykket behandling av utløsende årsak gir vanligvis tilbakegang av respirasjonssvikten 
- Bilaterale, diffuse lungefortetninger

- Utelukking av kardial årsak til respirasjonssvikten

- $p_{\mathrm{a}} \mathrm{O}_{2} / \mathrm{F}_{\mathrm{i}} \mathrm{O}_{2} \leq 26,7 \mathrm{kPa}(200 \mathrm{~mm} \mathrm{Hg})$

Det samme sykdomsbildet, men med en mindre alvorlig lungesvikt, klassifiseres som «acute lung injury» (ALI). På norsk er betegnelsen «akutt lungeskade». Skadede lunger blir lett infiserte. Bakterielle pneumonier kan være utgangspunkt for sepsis, som igjen kan utløse akutt lungesviktsyndrom. Liknende respirasjonssvikt kan utløses av bl.a. rusmidler og forgiftninger (3) samt transfusjoner (4). Definisjonsmessig kan derfor både pneumoni og de fleste andre årsaker til direkte skade av lungene inngå $\mathrm{i}$ begrepet «akutt lungesviktsyndrom» (ramme 1).

\section{Forekomst}

I et skandinavisk materiale fra 1999 beregnet man en insidens på 17,9 tilfeller av akutt lungeskade per 100000 personer per år (5). Data fra USA indikerer en forekomst på 78,9 tilfeller (6). Tall som angir forekomsten av akutt lungesviktsyndrom varierer med en faktor på ti mellom forskjellige land (7). Divergensene kan skyldes variasjoner i tolking av sykdomsdefinisjonen, ulik tilgjengelighet til helsetjenester, forskjeller i bruk av intensivbehandling eller ulike rapporterings- og registreringsrutiner. Sannsynlig forekomst er innen området $20-75$ pasienter per 100000 personer per år (8).

\section{Utløsende faktorer}

Vev som utsettes for mekanisk eller kjemisk skade, infeksjon eller hypoksi, frigjør molekyler med proinflammatoriske egenskaper (9). Samtidig kan endotelets overflate endres slik at dette både induserer koagulasjon (10) og aktiverer nøytrofile granulocytter og andre leukocytter. Kombinasjonen av proinflammatoriske agenser varierer med de utløsende faktorer. Bakterietoksiner, celleeller fettfragmenter, aktiverte komplementfaktorer og proinflammatoriske cytokiner er viktige. I tillegg induseres endringer i celleoverflate og syntesemønster hos f.eks. endotelceller, nøytrofile granulocytter, monocytter og makrofager (11). Enhver sykdom eller skade som kan indusere en generell inflammatorisk respons kan også utløse et akutt lungesviktsyndrom (ramme 1).

\section{Patofysiologi}

$\emptyset$ demdanning

I akuttfasen dannes økte mengder proteinrik ødemvæske i alveolene. Dette skyldes økt permeabilitet for proteiner og væske i lungekarene. Karenes hydrostatiske trykk kan være normale. Ødemdanningen er sjelden så massiv at ødemvæske kommer opp i de øvre luftveier. Alveolepitelets evne til å resorbere ødemvæske fra alveolene er nedsatt. Proteiner som inngår i koagulasjonskaskaden, lekker ut med ødemvæsken og gjør at denne blir som en gel når aktiverte makrofager og monocytter stimulerer koagulasjonen (11). Kombinasjonen av ødelagt cellemateriale og koagulerte plasmaproteiner danner typiske hyaline membraner i de små luftveiene (12).

\section{Generell betennelse}

Betennelsesreaksjonen gjør at nøytrofile granulocytter binder seg til endoteloverflaten og deretter vandrer ut i vevet. Når de stimuleres av proinflammatoriske agenser fra blod eller fra lokale celler i lungene, utskiller de store mengder reaktive oksygenforbindelser og vevsnedbrytende enzymer (13). Denne reaksjonen skader både endotel og type 1-pneumocytter i alveolene og bryter ned lungevevet. Også andre immunkompetente celler deltar i betennelsesutviklingen.

\section{Endotel og koagulasjon}

Påvirkning av bakterietoksiner og proinflammatoriske cytokiner kan endre endotelcellenes overflate, de går fra å ha antikoagulante til å ha prokoagulante egenskaper (10). Aktivering av trombocytter og koagulasjonskaskaden fører til trombosering i lungenes mikrosirkulasjon. Dette endrer perfusjonsforholdene og øker lungekarmotstanden, med fare for høyre ventrikkel-svikt.

\section{Fibroproliferativ fase}

Etter den akutte betennelses- og ødemfasen følger en fase med resorpsjon av væske og reparasjon av ødelagt vev. Selv om noe av lungevevet forblir skadet og omdannes til arrvev, vil mesteparten av det affiserte lungevevet gjenvinne normal funksjon (14). Hos noen pasienter skjer det en kraftig innvekst av bindevevsceller. Lungene hos slike pasienter forblir fibrotiske og stive selv om oksygeneringsevnen bedres. Et slikt forløp er assosiert med dårligere overlevelse (14).

\section{Behandling}

Pasienter som fyller kriteriene for akutt lungesviktsyndrom behandles i overvåkingseller intensivavdelinger. Det finnes i dag ingen spesifikk profylakse mot eller kausal behandling av syndromet når dette skyldes en ikke-infeksiøs betennelsesprosess. Ikke-steroide antiinflammatoriske midler (NSAID) har ingen beskyttende effekt og påvirker ikke sykdomsforløpet (15). Kortikostereoider, som kan ha gunstig effekt hos enkeltpersoner, bedrer ikke overlevelsen i større pasientpopulasjoner (16).

Behandlingen bygger derfor på to hovedprinsipper. Det forste er at rask og riktig behandling av utløsende skade/sykdom vil redusere produksjonen av proinflammatoriske og prokoagulante agenser. Noen av prinsippene for behandling av utløsende skade/sykdom er: - Tidlig stabilisering av frakturer ved traumer

- Målrettet og aggressiv sjokkbehandling med rask restitusjon av vevsoksygeneringen

- Optimalisering av infeksjonsbehandlingen

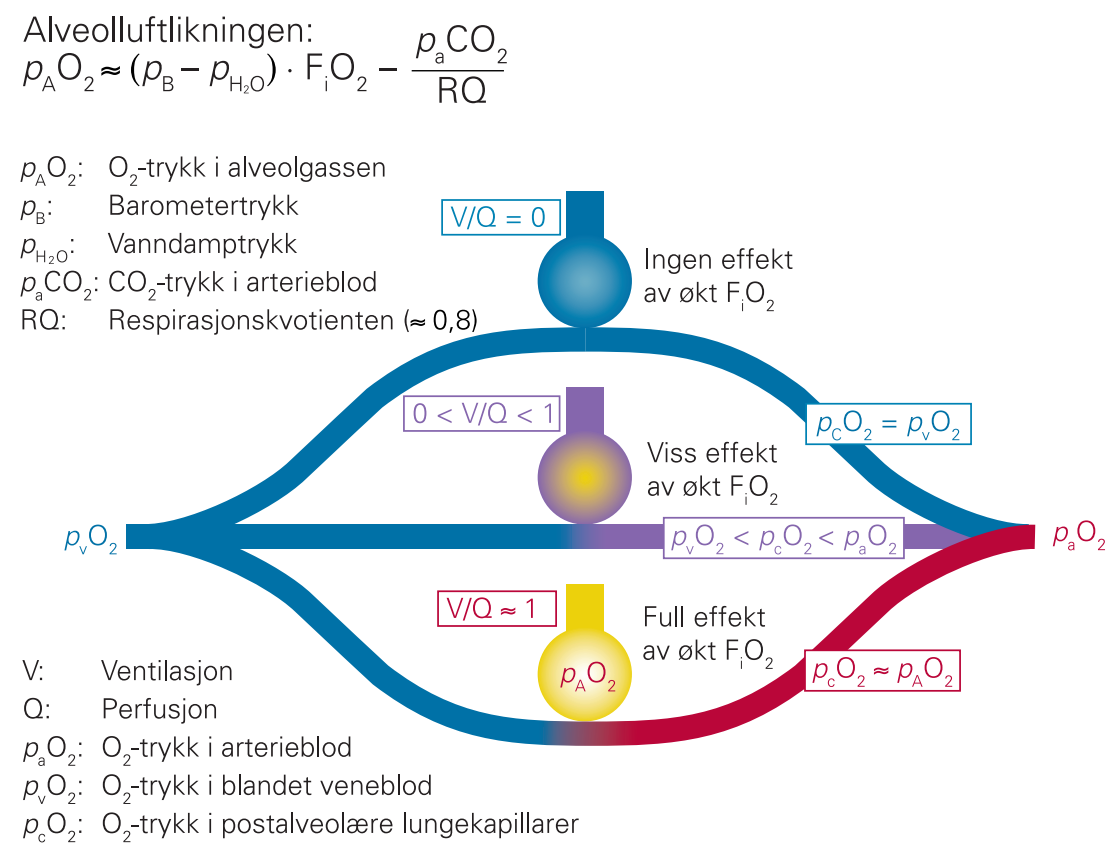

Figur 1 Alveolluft og lungeshunt. Alveolluftens oksygentrykk, $p_{A} \mathrm{O}_{2}$, bestemmes av barometertrykk, trykket av $\mathrm{CO}_{2}$ i alveolene og oksygenfraksjonen i inspirasjonsluften. Normalt øker $\mathrm{pO}_{2}$ i forbipasserende lungekapillærer $i$ takt med $p_{A} \mathrm{O}_{2}$. Ved lungeshunt avhenger effekten av økt $\mathrm{O}_{2} i$ inspirasjonsluften av forholdet mellom normalt ventilerte $(V / Q \approx 1)$, dårlig ventilerte $(0<V / Q<1)$ og ikkeventilerte $(V / Q=0)$ alveoler, $d v s$. shuntfraksjonen i lungene. Behandling som konverterer dårlig ventilerte alveoler til godt ventilerte og ikke-ventilerte til ventilerte, eller som øker $\mathrm{O}_{2}$-innholdet $i$ blandet venøst blod $\left(\mathrm{C}_{V} \mathrm{O}_{2}\right)$ ved å bedre forholdet mellom $\mathrm{O}_{2}$-tilbud og -forbruk, vil alltid øke $p_{a} \mathrm{O}_{2}$ 


\section{Ramme 1}

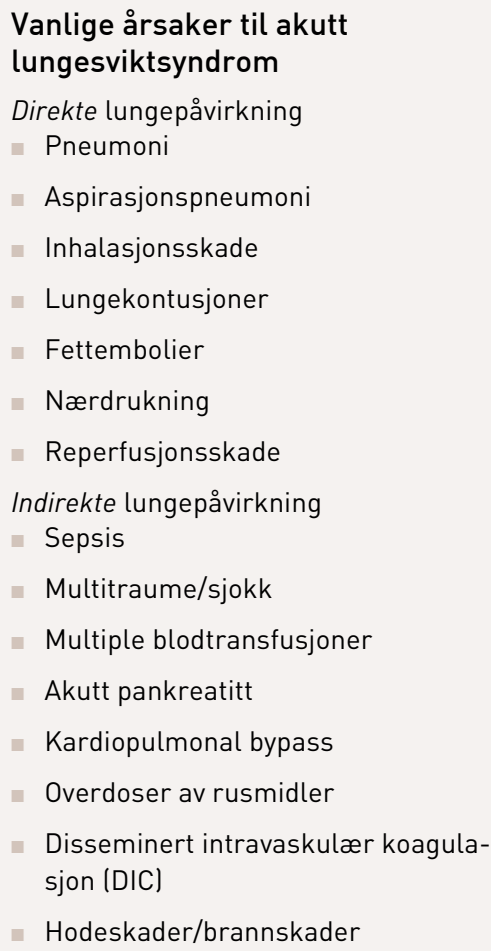

Det andre er at man må opprettholde tilfredsstillende oksygentilbud til organismen mens man venter på at de utløsende sykdomsprosesser kommer under kontroll og lungefunksjonen bedres. Dette hindrer at vevshypoksi kompliserer de utløsende sykdomsprosesser ytterligere eller medvirker til dysfunksjon eller svikt av flere organer.

Økning av oksygenmengden i inspirasjonsluften har ofte dårlig effekt ved akutt lungesviktsyndrom. Ikke-invasiv respirasjonsstøtte via ansiktsmaske har også begrenset effekt. Intervensjoner som øker antallet vel ventilerte alveolområder gir derimot en betydelig bedring (fig 1), og overtrykksventilasjon med respirator er hjørnesteinen i behandlingen av alvorlig respirasjonssvikt. I akuttfasen forutsetter behandlingen vanligvis anestesi, intubasjon og dyp sedasjon. Kombinasjonen av anestesi/sedasjon og overtrykksventilasjon har ofte negative sirkulatoriske effekter hos normo- og hypovolemiske personer. Overtrykksventilasjon øker intratorakalt trykk og nedsetter hjertets diastoliske fylling og minuttvolum, og medikamentelt betinget vasodilatasjon aksentuerer endringene. Ved uendret $\mathrm{O}_{2}$-forbruk vil redusert hjerteminuttvolum redusere $\mathrm{O}_{2}$-innholdet $\mathrm{i}$ arterieblodet hos pasienter med konstant lungeshunt (fig 1).

Moderne respiratorer har mange ventilasjonsmodi, men de grunnleggende prinsippene for respiratorbehandling $\mathrm{i}$ akuttfasen er likevel enkle. Lungene ventileres vanligvis med tidevolumer $\mathrm{i}$ området $6-9 \mathrm{ml}$ per kilo idealvekt. Atelektasetendens ved slut- ten av ekspirasjonen hindres ved å opprettholde et positivt trykk i luftveiene under hele ekspirasjonsfasen (positivt endeekspiratorisk trykk, PEEP). Utbredelsen av sykdomsprosessen i lungene er viktig for valg av tidevolum og PEEP-nivå. På grunnlag av data fra en større multisenterundersøkelse (17) har flere ekspertgrupper anbefalt et standardisert tidevolum på $6 \mathrm{ml}$ per kilo idealvekt for alle pasienter med akutt lungesviktsyndrom. Dokumentasjonen for at dette gir optimalt resultat for alle pasienter er imidlertid usikker (18). På grunn av store variasjoner i lungenes status hos pasienter med akutt lungesviktsyndrom bør tidevolum og PEEPnivå tilpasses individuelt, samtidig som målsettingen bør være å velge de laveste tidevolumer som gir tilfredsstillende oksygenering og $\mathrm{CO}_{2}$-kontroll. Hos pasienter hvor atelektaser øker oksygeneringsproblemene, har ofte intermitterende hyperinflasjon av lungene (rekruttering) en gunstig effekt.

Fordi ødem er en integrert del av sykdomsbildet i første fase, ønsker man å redusere lungekartrykkene. Hvis redusert væsketilførsel nedsetter hjerteminuttvolumet, kan det arterielle $\mathrm{O}_{2}$-innholdet paradoksalt nok synke når oksygenmengden $\mathrm{i}$ veneblodet faller, selv om shuntfraksjonen er konstant eller bedres (fig 1). Optimalisering av hjerteminuttvolumet ved å øke hjertets endediastoliske fylling gir høyere hydrostatiske trykk i lungekarene og mer ødemdanning. Dermed øker shuntens størrelse. Økt oksygenmengde $\mathrm{i}$ veneblodet kan likevel gi en høyere $p_{\mathrm{a}} \mathrm{O}_{2}$. Ofte velger man å holde hjertets fyllingsvolum på et suboptimalt nivå og øker kontraktiliteten i myokard med infusjoner av inotrope agenser.

Mange intervensjoner og medikamentelle behandlingsregimer har vist lovende resultater i dyreeksperimentelle studier og i studier med få pasienter. Stereoidbehandling, annen antiinflammatorisk behandling, vending i mageleie, høyfrekvent ventilasjon (jetventilasjon, oscillatorisk ventilasjon), inhalasjon av nitrogenmonoksid og instillasjon av surfaktant i luftveiene er noen av de intervensjonene som har vært prøvd. Selv om flere av intervensjonene bedrer lungefunksjonen på kort sikt hos mange pasienter, har ingen av dem gitt signifikant bedring av overlevelsen (hos voksne) ved utprøvning i større studier (19-22).

Enkelte utvikler katastrofal og behandlingsresistent lungesvikt og dør som følge av generalisert vevshypoksi. Ved livstruende oksygeneringssvikt økes PEEP-nivået ofte til $14-20 \mathrm{~cm} \mathrm{H}_{2} \mathrm{O}$, inspirasjonstiden forlenges i forhold til ekspirasjonstiden (invers ratio-ventilasjon) og ventilasjon i mageleie prøves. Hjertets minuttvolum økes med katekolamininfusjoner for å heve oksygenmetningen i blandet venøst blod. Hvis dette ikke bedrer tilstanden, prøves eventuelt høydose steroider (det gjelder fortrinnsvis pasienter uten sepsis), eventuelt kjøles pasienten ned for å redusere organismens $\mathrm{O}_{2}$-forbruk. Den ultimate behandling av katastrofal lungesvikt er å oksygenere blodet utenfor kroppen (ekstrakorporal membranoksygenering, ECMO). Dette gjøres ved hjelp av en hjertelunge-maskin - blod med lavt $\mathrm{O}_{2}$-innhold hentes ut fra en stor vene, oksygeneres og pumpes tilbake til sirkulasjonen på venesiden (hvis tilfredsstillende hjertefunksjon) eller på arteriesiden (hvis hjertefunksjonen samtidig svikter). Behandlingen er svært ressurskrevende og er derfor gjerne bare aktuell hos personer hvor lungene er det eneste organet med alvorlig svikt (23).

Behandling som ikke er vist å gi bedre overlevelse, er å anse som udokumentert kriseintervensjon. Hvis behandlerne tidligere har erfart eller kjenner til at enkeltpasienter har respondert positivt på slik behandling, er det likevel logisk å prøve også slike alternativer ved livstruende hypoksemi på tross av optimal respiratorinnsats. Hvis behandlingen innebærer fare for ytterligere komplikasjoner og/eller medfører svært høyt ressursforbruk, bør forholdet mellom risiko og sannsynlig gevinst for pasienten overveies grundig før oppstart.

\section{Prognose}

Dødeligheten av respirasjonssvikt rapporteres i området fra $33 \%$ (akutt lungeskade) til opptil $70 \%$ (akutt lungesviktsyndrom) (24). Som for beregninger av forekomst varierer tallene betydelig fra studie til studie og sannsynligvis av de samme årsaker. Tall som bygger på dødelighet i kontrollgruppen ved multisenterstudier $(25-30 \%)$ kan være villedende (20), da pasienter med andre alvorlige risikofaktorer $\mathrm{i}$ tillegg til respirasjonssvikten ofte blir ekskludert fra slike studier.

Hos de fleste med akutt lungesviktsyndrom er svikten reversibel hvis grunnsykdommen er det. Død som en direkte følge av lungesvikt ses imidlertid hos bare 10-15\% av pasientene (25). De fleste dør som følge av at flere organer enn lungene svikter (multiorgansvikt) - summen av de patofysiologiske problemene blir for stor. Grunnsykdommen, kombinert med eventuelle preeksisterende tilleggssykdommer og alder, har derfor betydning for overlevelsen hos slike pasienter. Ved økende alder ser man også at dødeligheten hos intensivpasienter målt ett år etter intensivoppholdet er dobbelt så høy som dødeligheten i selve intensivavdelingen (26). Akutt respirasjonssvikt med alvorlig sepsis som underliggende årsak er forbundet med høyest dødelighet, mens de pasientene hvor respirasjonssvikten utløses av skader (multitraumer) har best prognose (27). De som overlever, kan gjenvinne en tilnærmet normal lungefunksjon.

Oppgitte interessekonflikter: Ingen 


\section{Litteratur}

1. Ashbaugh DG, Bigelow DB, Petty TL et al. Acute respiratory distress in adults. Lancet 1967; 2: 319-23.

2. Bernard GR, Artigas A, Brigham KL et al. Report on the American-European consensus conference on ARDS: definitions, mechanisms, relevant outcomes and clinical trial coordination. The Consensus Committee. Intensive Care Med 1994; 20: 225-32

3. Wilson KC, Saukkonen JJ. Acute respiratory failure from abused substances. J Int Care Med 2004; 19: 183-93.

4. Silliman CC, Boshkov LK, Mehdizadehkashi Z et al. Transfusion-related acute lung injury: epidemiology and a prospective analysis of etiological factors. Blood 2003; 101: 454-62.

5. Luhr OR, Antonsen K, Karlsson M et al. Incidence and mortality after acute respiratory failure and acute respiratory distress syndome in Sweden, Denmark, and Iceland. The ARF study group. Crit Care Med 1999; 159: 1849-61.

6. Rubenfeld GD, Caldwell E, Peabody E et al. Incidence and outcomes of acute lung injury. $\mathrm{N}$ Engl J Med 2005; 353: 1685-93.

7. Brun-Buisson C, Minelli C, Bertolini G et al. Epidemiology and outcome of acute lung injury in European intensive care units: results from the ALIVE study. Intensive Care Med 2004; 30: 51-61.

8. Goss CH, Brower RG, Hudson LD et al. Incidence of acute lung injury in the United States. Crit Care Med 2003; 31: 1301-8.

9. Bhatia M, Moochhala S. Role of inflammatory mediators in the pathophysiology of acute respiratory distress syndrome. J Pathol 2004; 202: $145-56$
10. Orfanos SE, Mavrommati I, Korovesi I et al. Pulmonary endothelium in acute lung injury: from basic science to the critically ill. Intensive Care Med 2004: 30: 1702-14

11. Surratt BT, Parsons PE. Mechanisms of acute lung injury/acute respiratory distress syndrome. Clin Chest Med 2006; 27: 579-89

12. Peñuelas O, Aramburu JA, Frutos-Vivar F et al. Pathology of acute lung injury and acute respiratory distress syndrome: a clinical-pathological correlation. Clin Chest Med 2006; 27: 571-8.

13. Craddock PR, Fehr J, Brigham KL et al. Complement and leukocyte-mediated pulmonary dysfunction in hemodialysis. N Engl J Med 1977: 296: 769-74.

14. McHugh LG, Milberg JA, Whitcomb ME et al. Recovery of function in survivors of acute respiratory distress syndrome. Am J Respir Crit Care Med 1994: 150: 90-4

15. Bernard GR, Wheeler AP, Russell JA et al. The effect of ibuprofen on the physiology and survival of patients with sepsis. N Engl J Med 1997: 336: 912-8.

16. Bernard GR, Luce JM, Sprung CL et al. High dose corticostereoids in patients with the adult respiratory distress syndrome. N Engl J Med 1987: 317: 1565-70.

17. The Acute Respiratory Distress Syndrome Network. Ventilation with lower tidal volumes as compared with traditional tidal volumes for acute lung injury and the acute respiratory distress syndrome. N Engl J Med 2000; 342: 1301-8.

18. Deans KJ, Minneci PC, Banks SM et al. Mechanical ventilation in ARDS: one size does not fit all. Crit Care Med 2005; 35: 1141-3.
19. Andersen JB. Ventilatory strategy in catastrophic lung disease. Inversed ratio ventilation (IRV) and combined high frequency ventilation (CHVF). Acta Anaesthesiol Scand Suppl 1989; 90: 145-8.

20. Lundin, S, Mang H., Smithies M et al. Inhalation of nitric oxide in acute lung injury: results of a European multicenter study. Int Care Med 1999; 25: 911-9.

21. Gattinoni L, Tognoni G. Pesenti A et al. Effect of prone positioning on the survival of patients with acute respiratory failure. N Engl J Med 2001; 345: 568-73.

22. Wheeler AP, Bernard GR. Acute lung injury and the acute respiratory distress syndrome: a clinical review. Lancet 2007; 369: 1553-65.

23. Chalwin RP, Morgan JL, Graham PL. The role of extracorporeal membrane oxygenation for treatment of the adult respiratory distress syndrome: review and quantitative analysis. Anaesth Intensive Care 2008; 36: 152-61.

24. Leaver SK, Evans TW. Acute respiratory distress syndome. BMJ 2007; 335: 389-94.

25. Fowler AA, Hamman RF, Zerbe GO et al. Adult respiratory distress syndrome: prognosis after onset. Am Rev Respir Dis 1985; 132: 472-8.

26. Djaiani G, Ridley S. Outcome of intensive care in the elderly. Anaesthesia 1997; 52: 1130-6.

27. MacCallum NS, Evans TW. Epidemiology of acute lung injury. Curr Opin Crit Care 2005; 11: 43-9.

Manuskriptet ble mottatt 17.6. 2008 og godkjent 30.7. 2009. Medisinsk redaktør Are Brean. 